\title{
T-CELL GAMMA/DELTA HEPATOSPLENIC LYMPHOMA - PROLONGED REMISSION INDUCED BY AGGRESSIVE FIRST LINE TREATMENT
}

\author{
Vít Procházka ${ }^{\mathrm{a}}$, Tomáš Papajík ${ }^{\mathrm{a}}$, Marie Jarošováa ${ }^{\mathrm{a}}$ Zuzana Pikalováa, Karel Indrák ${ }^{\mathrm{a}}$, \\ Martin Tichýb, Ladislava Kučerováb, František Fakan ${ }^{c}$, Milan Bílýd, David Starostka ${ }^{d}$
}

a Department of Hemato-oncology, Teaching Hospital, Olomouc, Czech Republic

${ }^{b}$ Department of Pathology, Teaching Hospital, Olomouc, Czech Republic

c Department of Pathology, Medical Faculty, Charles University, Plzeň, Czech Republic

${ }^{d}$ Department of Hematology, General Hospital, Havírov, Czech Republic

Received: May 2, 2005; Accepted (with revisions): October 10, 2005

Key words: Hepatosplenic lymphoma/Treatment/Autologous/Transplant/Cytogenetics/Immunophenotype

T-cell gamma/delta hepatosplenic lymphoma is a primary extranodal lymphoma, distinct from other T/LGL lymphomas. The clinical course is aggressive, and despite use of the multiagent chemotherapy and young age of the patients, the median survival is less than 1 year. Curability of this disease is still uncertain. We reported a case of the succesfull intensive treatment with splenectomy, chemotherapy a first line autologous stem cell transplant. High intensity cytarabine-platinum containing regimen (EDHAP) may overcome primary resistance to conventional alkylating agents.

\section{INTRODUCTION}

T-cell gamma/delta hepatosplenic lymphoma is a rare, well defined entity with typical immunophenotype, resistance to chemotherapy and short survival ${ }^{1,3,4,5}$. It is derived from cytotoxic T-lymphocytes, which are preferentially located at the extranodal sites - red splenic pulp, skin, liver, intestine and bone marow. The neoplastic cells are CD $3+$ and usually TCR (T-cell receptor) $\delta 1+$, TCR $\alpha / \beta$ negative, CD 56 \pm , CD4 negative, CD8 negative and CD5 negative ${ }^{6}$. Most of the studied cases had nonactivated cy-

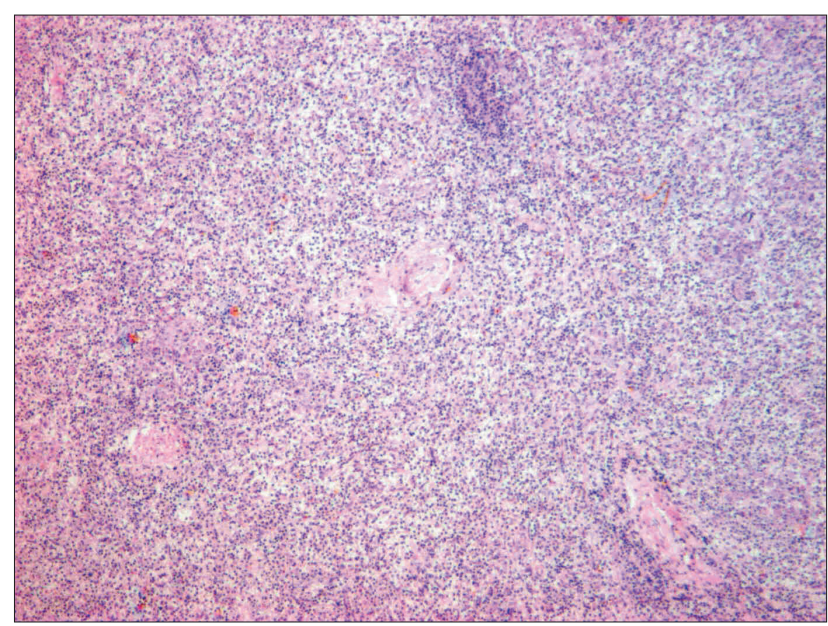

Fig. 1. Histopathology of the spleen. Hematoxylin-eosin. Marked hyperplasia of the red pulp. Medium sized neoplastic cells are located within the cords and sinuses. totoxic phenotype: T-cell intracellular antigen-1 (TIA-1) + and granzyme negative $e^{1,4}$.

\section{METHODS}

A 48-year-old female was referred to our hospital with pancytopenia, splenomegaly $(22 \mathrm{~cm})$ and weight loss. There was no evidence of enlarged lymph nodes or hepatomegaly on the CT scan. We indicated splenectomy to reduce tumor mass and to eliminate hypersplenism.

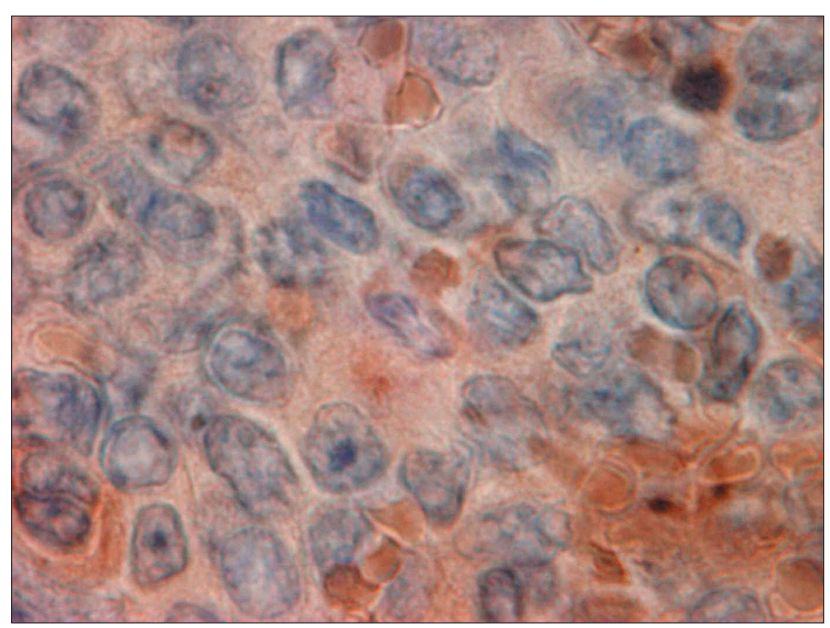

Fig. 2. Histopathology of the spleen - high magnification (Obj. magn. × 100). Immunohistochemistry - CD 8 . Tumor cells are CD 8 negative. 


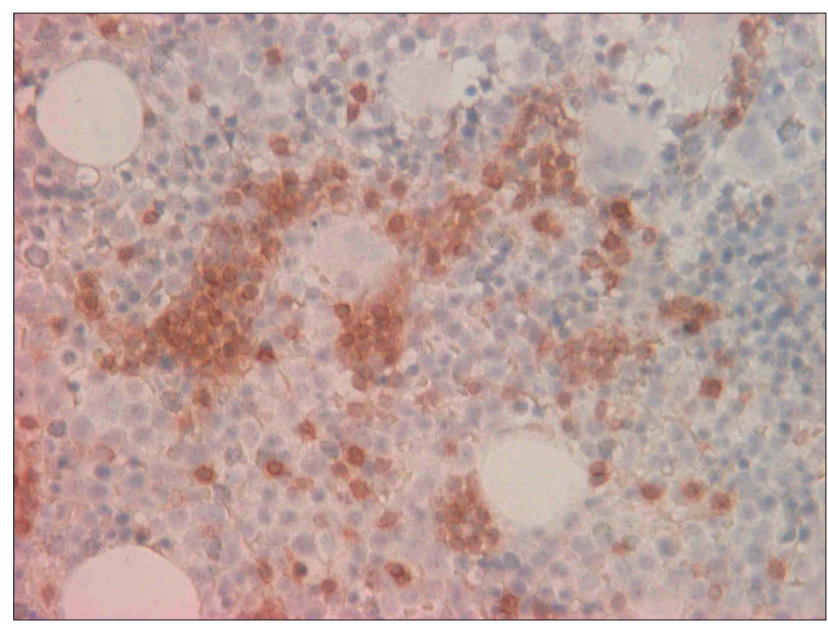

Fig. 3. Bone marrow histology - immunohistochemistry - CD3. Hypercellularity, sinusal infiltrate composed of atypical neoplastic CD 3+ lymfocytes.

Histopathological examination showed infiltration of the splenic red pulp by small to medium sized pleomorphic lymphocytes CD 3+, granzyme B+, TIA-1+ and perforin+. Immuno-flow cytometry of peripheral blood, bone marrow and spleen samples verifed atypical lymphocytes, which were CD 2+, CD 3+, CD 7+, CD 5 negative, CD 4 negative/CD 8 negative, CD 56+ and TCR g/d+. Clonal rearrangement of TCR delta was confirmed by multiplex PCR (spleen). Conventional cytogenetic analysis (spleen) showed complex chromosomal aberrations. Fluorescence in situ hybridization (FISH) did not verify rearrangement of IgH (immunoglobulin heavy chain gene), ALK/NPM (anaplastic lymphoma kinase gene/nucleophosmin gene) or $\mathrm{i}(7 \mathrm{q})$.

The patient was treated with 3 cycles of cytarabineplatinum containing regimen (EDHAP), 1 cycle of methotrexate-based regimen (IVAM) and 1 cycle of high-dose cytarabine (HAM) followed by high-dose chemotherapy (conditioning regimen BEAM 200) and autologous stem cell transplant.

\section{RESULTS}

The patient achieved complete remission (CR) in bone marrow in January 2004 after 2 cycles of chemotherapy (EDHAP). She remains in CR 21 months after diagnosis and 16 months after stem cell transplant.

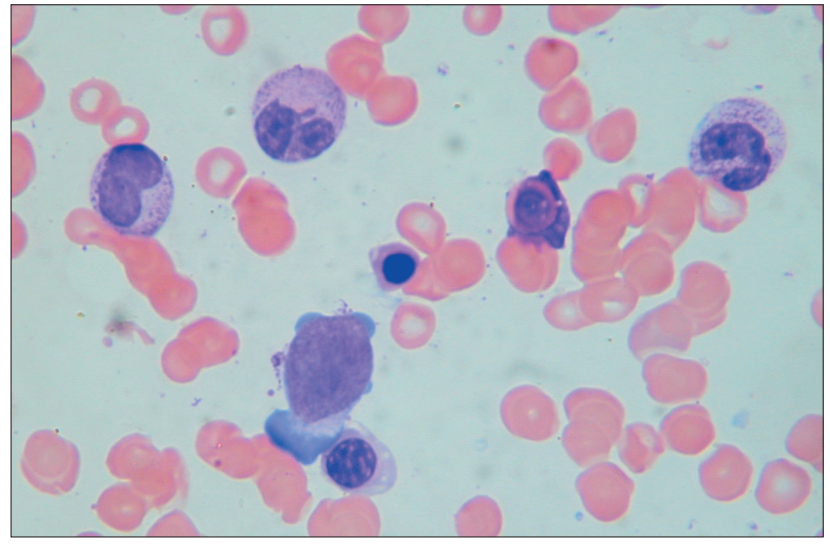

Fig. 4. Bone marrow smear. Atypical neoplastic lymphoid cell. Obj. magn. $\times 100$.

\section{CONCLUSION}

Current treatment modalities appear to be ineffective in most patients. Our case report suggests that aggressive first line treatment with platinum-cytarabine containing regimen followed by high-dose chemotherapy may lead to prolonged remission of gamma/delta hepatosplenic lymphoma ${ }^{1,2}$. More studies are needed to determine the frequencies of immunophenotypes (activated versus nonactivated T-cells) and genetic changes, such as isochromosome arm 7q $\left(\right.$ ref. $\left.^{1,4}\right)$. Gamma/delta T-cell lymphoma is probably not an homogenous entity. Precise identification of tumor cell origin is the first step to finding valuable prognostic factors.

\section{REFFERENCES}

1. Belhadj K, Reyes F. (2003) Hepatosplenic $\gamma \delta$ T-cell lymphoma is a rare clinicopathologic entity with poor outcome: report on series of 21 patients. Blood 102, 4261-4269.

2. Chanan-Khan A, Islam T. (2004) Long-term survival with allogenic stem cell transplant and donor lymphocyte infusion following salvage therapy with anti-CD 52 monoclonal antibody (Campath) in a patient with alpha/beta hepatosplenic T-cell non-Hodgkin's lymphoma. Leuk Lymphoma 45, 1673-5.

3. Taguchi A, Miyazaki M. (2004) Gamma/delta T cell lymphoma. Intern Med 43, 120-5.

4. Jaffe ES, Harris NL, Stein H, Vardiman JW. WHO Classification of Tumours: Tumours of Haematopoietic and Lymphoid Tissue. Lyon: IARC Press, 2001.

5. Greer JP, Kinney MC. T-cell and NK Cell lymphoproliferative Disorders. In: Schechter GP, Hoffman R, Schrier SL, editors. American Society of Hematology Education Book, ASH 2001. P. 259-274.

6. Cooke C.B., Krenacs L., Stetler-Stevenson M. et al. (1996) Hepatosplenic T-cell Lymphoma: A Distinct Clinicopathologic Entity of Cytotoxic $\gamma \delta$ T-cell Origin. Blood, 88, 4265-4274 